\title{
Phenomenology of the "hardiness" concept in the post-boarding socialization continuum of youth in modern Russian society
}

\author{
Elena Bayer ${ }^{1 *}$, Stepan Avakov ${ }^{1}$, Nikolai Kurianov $^{1}$, and Tatyana Zhukova ${ }^{2}$ \\ ${ }^{1}$ Don State Technical University, 344002, Rostov-on-Don, Russia \\ ${ }^{2}$ Rostov State Medical University, 344022, Rostov-on-Don, Russian
}

\begin{abstract}
The article focuses on studying the phenomenon of "hardiness" of orphans and children left without parental care, reveals the level of hardiness qualities in adolescent orphans of senior high school. The components of hardiness are shown and the main directions in its study are highlighted. It has been proved that hardiness is directly interconnected with many positive personal characteristics and contributes to health preservation and increased efficiency. The author comes to the following conclusions: - resilience is one of the most powerful resources that contribute to improving the physical and mental health of orphans and children left without parental care for successful adaptation in stressful situations and solving difficult life situations; - in the course of conducting an empirical study, it was found that about $70 \%$ of orphans of the pregraduation and final classes have a low or below average level of readiness for post-international socialization; - of particular importance are the issues of the need to create a set of measures (training programs, teacher mentoring programs, etc.) to improve the overall level of resilience, as well as its components for the most favorable post-international socialization of orphans.
\end{abstract}

\section{Introduction}

Nowadays, it seems relevant to consider the hardiness of orphans and children left without parental care as a basic resource for overcoming life difficulties and forming the ability to manage life events.

The psychological readiness of an orphanage senior student for post-boarding socialization is a complex structural process resulting from organizing activities aimed at preparing the high school student for an independent life. In our opinion, it is the level of hardiness and age-determined development of the cognitive, motivational and volitional, emotional spheres, skills and abilities that ensure integration into society and possible selfrealization in it thus contributing to successful post-boarding socialization.

The purpose of our research is to study hardiness levels of adolescent orphans and children left without parental care of pre-graduation and graduation age (15-16 years).

\footnotetext{
*Corresponding author: elenabaier@list.ru.
} 
The object of the research is hardiness of adolescent orphans and children left without parental care who study in senior high school.

The subject of the research is hardiness characteristics of senior high school orphans and children left without parental care.

\section{Materials and Methods}

We used the following methods in our study:

- theoretical: analysis of psychological and pedagogical literature on the issues under study;

- empirical methods: "Hardiness Survey" by S.R. Maddi adapted by E.N. Osin and E.I

Rasskazova [1]; a technique for diagnosing the real structure of personal value orientations modified by C.R. Rogers and R.F. Dymond [2]; methodology for diagnosing the socialization of a person modified by M.I. Rozhkov [3]; methodology for diagnosing the level of developing social skills by O.V. Trishina [4]; methodology for diagnosing value orientations - the Rokeach Value Survey [5]; a technique for diagnosing the real structure of personal value orientations by S.S. Bubnova [6];

- quantitative and qualitative analysis of the results obtained.

The study involved 64 boarding school leavers in the Rostov region (Azov, Rostov-onDon) aged 15-16 years.

\section{Results}

The empirical study was carried out in order to identify the level of graduate and undergraduate orphans' readiness for post-boarding socialization. The study involved 64 adolescents aged 15-16 years from institutions for orphans and children left without parental care in the Rostov region.

We used an adapted Russian version of Salvatore R. Maddi's Hardiness Survey [7] in our work.

The analysis of the diagnostics findings showed that adolescent orphans of school leaving age are characterized by an average level of hardiness. The adolescents' indicators on the "Involvement" scale are formed at the average level. The lowest values of the hardiness components were fixed on the scales of "control" and "risk taking". It is characteristic for adolescents to have a feeling of self-doubt; reduced values of involvement give rise to a feeling of rejection in some adolescents; a reduced level of "risk taking" was probably formed in adolescents as a result of deprivation conditions associated with a homogeneous living environment in an orphanage. The results are shown in Table 1.

Table 1. Test findings of the orphans' hardiness level

\begin{tabular}{|l|l|l|}
\hline Leading Values & & Average Score \\
\hline Involvement & & 20.83 \\
\hline Control & & 11.24 \\
\hline Risk taking & & 11.10 \\
\hline Hardiness & & 43.07 \\
\hline
\end{tabular}

In addition, the study included the socio-psychological adaptability test worked out by C.R. Rogers and R.F. Dymond [2], which made it possible to establish the peculiarities of the orphans' adaptation period through the integral indicators of "adaptability", "self- 
acceptance", "acceptance of others", "emotional comfort", "internality", "desire to dominate".

For the most part, an average level of adaptability has been recorded in the group of orphans with a clear tendency to the low indicator (43\%). There are no indicators with high values. The indicator of "self-acceptance" is formed at an average level (56\%), "acceptance of others" is average (52\%), the indicator of "emotional comfort" is average with a tendency to low (48\%), "internality" is formed at a low level (39\%), "desire to dominate" is average $(50 \%)$. The research results are presented in Table 2.

Table 2. Test findings of the real personal value orientations structure after C. Rogers and R. Dymond

\begin{tabular}{|l|l|}
\hline Scales & Integral indicators (\%) \\
\hline Adaptability & 43 \\
\hline Self-acceptance & 56 \\
\hline Acceptance of others & 52 \\
\hline Emotional comfort & 48 \\
\hline Internality & 39 \\
\hline Desire to dominate & 50 \\
\hline
\end{tabular}

In turn, within the framework of our study, we attempted to assess the personal socialization of adolescent orphans and children left without parental care according to M.I. Rozhkov's method [3].

The test findings showed that the orphans and children left without parental care demonstrated an insufficient level of preparedness for an independent life. In general, the average level of socialization prevailed with a tendency to a low level $(\mu=2.26 \pm 0.71)$.

The average level was recorded in terms of "social adaptability" $(\mu=2.21 \pm 0.53)$, "autonomy" $(\mu=2.6 \pm 0.64)$, "social norms" $(\mu=2.32 \pm 0.4)$. According to the authors of the methodology, one can focus on the fact that the obtained indicators allow us to speak of problems concerning the generally accepted norms and rules of behaviour. At the same time, very low values were revealed for the "social activity" indicator $(\mu=1.9 \pm 0.38)$ reflected in the uncertainty or inconsistency of life choices. As a result, the adolescent orphans are subject to situational influence. Any change in social conditions entails correction of their orientation and life plans, the adolescents are not fully ready for an independent "adult" life, therefore, they associate success in life not only with their abilities and personal initiative but also with some external circumstances that do not depend on them. The test results are presented in Table 3.

Table 3. Test findings of socialization levels of orphans and children deprived of parental care based on M.I. Rozhkov's method

\begin{tabular}{|l|l|}
\hline Scales & Values, scores \\
\hline Social adaptability & 2.21 \\
\hline Social autonomy & 2.60 \\
\hline Social activity & 1.90 \\
\hline Social norms & 2.32 \\
\hline Socialization level & 2.26 \\
\hline
\end{tabular}

Further, in the course of our research, the social skills level of orphans and children left without parental care was studied. The test findings have shown that, in general, the 
adolescents have initial social skills $(\mu=3.5 \pm 0.49)$, they also have minimal skills that allow them to come into contact with other people, as well as take part in a conversation. Difficulties with self-expression in conversation with other people have also been recorded $(\mu=2.82 \pm 0.58)$, in addition, the ability to express feelings and experiences is poorly formed, as well as the ability to convey information to other people (ask for help, make a complaint, convince someone in the correctness of their point of view, to express dissatisfaction, etc.). The indicators of adequate response to the opinion and experiences of another person are reduced $(\mu=2.7 \pm 0.77)$. The skills of planning future actions are not formed $(\mu=2.2 \pm 0.45)$; it is difficult for the adolescents to prepare for the upcoming action, to prioritize, to make a decision, to assess their competence. The skills of preventing and resolving conflict situations are formed at a low level, there are difficulties with finding an alternative to aggressive behaviour $(\mu=2.51 \pm 0.8)$.

The adolescents assess their peers' abilities higher $(\mu=3.72 \pm 0.62)$ than their own abilities $(\mu=3.14 \pm 0.57)$. With a relatively adequate perception of the social situation as a whole, the majority of the adolescents tend to underestimate their capabilities. Their behaviour is characterized by an increased level of anxiety and alertness in relationships with peers. The results are shown in Table 4.

Table 4. Test findings of the social skills levels of orphans and children left without parental care based on O.V. Trishina's method

\begin{tabular}{|l|l|}
\hline Scales & Values, scores \\
\hline Minimal skills & 3.50 \\
\hline Self-expression in conversation & 2.82 \\
\hline Reaction to the opinion of another person & 2.70 \\
\hline Skills for planning upcoming actions & 2.20 \\
\hline Alternatives to aggressive behaviour & 2.51 \\
\hline Average rating of their own social abilities & 3.14 \\
\hline Average rating of social abilities of their peers & 3.72 \\
\hline
\end{tabular}

An important segment in our study was testing the value orientations of orphans and children left without parental care in pre-graduation and graduation classes.

It is important to emphasize that, in our opinion, value orientations presuppose a certain readiness for action in accordance with the meanings of the individual which act as lifeorganizing principles and give direction to personal positions, actions, and behaviour in general. Students living in an institution for orphans and children left without parental care develop certain adaptive mechanisms associated with ideas about the family, social connections and relationships, but the family itself, as an intrinsic value, does not acquire the main importance in the adolescent's value system. The analysis of value orientations was based on the Rokeach Value Survey [5] combined with testing the real structure of personal value orientations based on the method worked out by S.S. Bubnova [6]. The results of value orientations research are shown in Table 5.

Table 5. Test findings of value orientations of orphanage senior students based on the Rokeach Value Survey

\begin{tabular}{|l|l|l|l|l|l|}
\hline Terminal values & $\begin{array}{l}\text { Average } \\
\text { score }\end{array}$ & Rank & $\begin{array}{l}\text { Instrumental } \\
\text { values }\end{array}$ & $\begin{array}{l}\text { Average } \\
\text { score }\end{array}$ & Rank \\
\hline An exciting life & 6.32 & 7 & Clean & 10.00 & 14 \\
\hline Wisdom & 9.48 & 10 & Polite & 9.11 & 10 \\
\hline
\end{tabular}




\begin{tabular}{|l|l|l|l|l|l|}
\hline Health & 6.89 & 11 & Ambitious & 5.68 & 2 \\
\hline An interesting job & 8.12 & 13 & Cheerful & 9.44 & 11 \\
\hline A world of beauty & 13.50 & 18 & Capable & 11.56 & 13 \\
\hline Love & 4.98 & 2 & Independent & 5.04 & 1 \\
\hline A comfortable life & 10.60 & 8 & Demanding & 7.83 & 6 \\
\hline True friendship & 7.52 & 6 & Intellectual & 7.54 & 4 \\
\hline Social recognition & 9.64 & 5 & Responsible & 9.02 & 15 \\
\hline Knowledge & 12.17 & 16 & Logical & 10.56 & 7 \\
\hline A productive life & 12.00 & 15 & Self-controlled & 9.72 & 12 \\
\hline Personal growth & 8.43 & 9 & Courageous & 7.62 & 5 \\
\hline Pleasure & 5.87 & 3 & Understanding & 10.80 & 16 \\
\hline Freedom & 4.65 & 1 & Tolerant & 6.47 & 3 \\
\hline Family security & 10.02 & 12 & Broad-minded & 12.47 & 18 \\
\hline National security & 11.15 & 14 & Strong will & 7.95 & 8 \\
\hline Creation & 13.25 & 17 & Honest & 9.58 & 17 \\
\hline Self-confidence & 6.94 & 4 & Efficient & 8.33 & 9 \\
\hline
\end{tabular}

So, we were able to find out that $64 \%$ of the orphans possess the value orientations aimed at freedom (rank 1), love (rank 2), pleasure (rank 3), self-confidence (rank 4), social recognition (rank 6). The following values take the last place: the world of beauty (rank 18), creation (rank 17), knowledge (rank 16), a productive life (rank 15).

This group of adolescents is characterized by an egoistic personality orientation, the value orientations connected with fulfilling social functions and competencies are not actualized in the adolescents' value system. The analysis of the instrumental values of the orphans and children left without parental care, brought up in a state establishment, has shown that $55 \%$ of the orphans are dominated by value orientations aimed at selfaffirmation and self-actualization. Among the priority instrumental values, the following were identified: independence (rank 1), high demands (rank 2), tolerance (rank 3), intellect (rank 4). The least priority values are: open-mindedness (rank 18), honesty (rank 17), understanding (rank 16), responsibility (rank 15). The adolescents strive for independence and self-realization, but at the same time the dominant instrumental values will not contribute to the achievement of what they want. The test findings concerning the real structure of the adolescents' value orientations are shown in Table 6.

Table 6. Test findings of the real structure of personal value orientations after S.S. Bubnova

\begin{tabular}{|l|l|}
\hline Leading values & Average score \\
\hline Pleasant pastime, recreation & 4.63 \\
\hline High material well-being & 3.13 \\
\hline Chasing and enjoying beauty & 2.75 \\
\hline Empathy and compassion for other people & 4.75 \\
\hline Love & 4.13 \\
\hline $\begin{array}{l}\text { Knowledge of new things in the world, } \\
\text { nature, man }\end{array}$ & 2.63 \\
\hline High social status and management of people & 3.00 \\
\hline $\begin{array}{l}\text { Recognition and respect of people and } \\
\text { influence on others }\end{array}$ & 4.63 \\
\hline $\begin{array}{l}\text { Social activity to achieve positive changes in } \\
\text { society }\end{array}$ & 2.88 \\
\hline
\end{tabular}




\begin{tabular}{|l|l|}
\hline Communication & 3.25 \\
\hline Health & 2.38 \\
\hline
\end{tabular}

The analysis of the research results concerning the realization of the value orientations of adolescent orphans in real life conditions has shown that help and mercy to other people (rank 1), a pleasant pastime (rank 2), recognition and respect of people, and influence on others (rank 2), and love (rank 3) dominate in the structure of their value orientations The predominance of such values in the real structure of value orientations may be due to the needs of the orphans and children left without parental care, i.e. a need to be loved and accepted by other people.

Thus, the results of testing the socio-psychological adaptation and the level of individual socialization have enabled us to distinguish two groups of adolescents: group 1 (21 people $-32 \%$ of the sample) includes adolescents with an average and above average level of readiness for post-boarding socialization and group 2 (43 people $-68 \%$ of the sample) includes adolescents with a level of readiness below average and low.

So, on the basis of the data obtained, we have constructed a psychological portrait of the first group of adolescent orphans with an average and above average level of readiness for post-boarding socialization that includes a number of features: social and psychological adaptability, self-esteem and the ability to respect others, understanding their problems and the desire to cope with them.

The general level of individual socialization in this group is the dominance of the motives connected with prestige and well-being, while the uncertainty of life choices is noted. As a result, the adolescents are exposed to the influence of the situational social context, when a change in social conditions entails a correction of their orientation and life plans.

The representatives of this group believe that they are not fully ready for an independent "adult" life, therefore, they associate success in life not only with their abilities and personal initiative, but also with some external circumstances beyond their control. They demonstrate adherence to the humanitarian norms of society, have some idea of the existing system of social relations, but at the same time experience difficulties in interpersonal communication. They show social activity, strive for social autonomy, but at the same time experience a number of difficulties of self-realization. The adolescents in this group are characterized by an average level of social skills and an adequate or slightly overestimated / underestimated assessment of their own social abilities and the abilities of their peers. They have adequate initial social skills that allow them to come into contact with other people, participate in conversation, they can express their feelings and experiences, and also transmit information to another person.

The second group of adolescent orphans has a slightly different psychological profile: their social maladjustment is manifested in rejection of themselves and others (conflict in relations with others); their protective "barriers" prevent them from understanding their actual experience and "solving" problems, or solving them at a subjective psychological level, in their own perception, but not in reality; they also demonstrate inflexibility of mental processes, avoid problem solving.

Their level of socialization is below average and characterized by a lack of interest in learning, the learning motivation is dominated by the motives of duty and avoidance of trouble. Interest in public events has been significantly reduced. In the structure of the value orientations of these adolescents, non-educational and non-professional values prevail. 


\section{Discussion}

To date, various researches by specialists, psychologists, teachers show that orphans and children left without parental care differ significantly from children living in a family in terms of mental and physical development.

Hardiness was first described by S. Kobasa as a set of interrelated personality traits or traits that distinguish "healthy" managers under stress from "unhealthy" [8]. S. Maddi [9] characterized hardiness as a combination of three interrelated components: involvement, control and risk taking. According to P.T. Bartone [10], hardiness is a generalized way of functioning of an individual that includes involvement (the belief that life is interesting and worthy), control (the belief that results can be controlled or influenced), and risk taking (an exploratory approach to life). The "hardy type" person has a strong future orientation or a tendency to look to the future by learning from the past.

The analysis of some foreign studies on this topic has shown that hardiness is generally considered here as a general indicator of a person's mental [11] and physical health [12]. In addition, researchers P.T. Bartone, D.R. Kelly, M.D. Matthews [13] note that hardiness consists of cognitive, emotional and behavioural characteristics and defines a person's ability to maintain a healthy state during turbulent times.

A study by Canadian researchers C.M. Kowalski and J.A. Schermer [14] explores the practical value of psychological hardiness and the difference between rumination and anxiety.

Both Russian and foreign researches focus on the characteristics of hardiness in relation to a number of diverse psychological phenomena, for people with a high level of hardiness are characterized by: stress resistance of the body, increased resistance to disease $[15 ; 16]$; reduced level of anxiety [17]; psychological well-being conditioned by the level of personal growth [18]; positive human functioning at the cognitive and emotional level [19]; psychological well-being conditioned by life satisfaction and the ratio of positive and negative emotions [20;21].

Some Russian researches focus on investigating foreign approaches to the study of the concept of "hardiness" [22], the hardiness model of orphans and children left without parental care based on physical culture and sports [23; 24]; the close relationship between personal hardiness and psychological safety and socio-psychological adaptation $[25,26]$.

So, the conducted analytical study has emphasized that, starting with the fundamental article by S.C. Kobasa, to the present date, a large number of scientific studies have been carried out, focusing on the impact of hardiness on psychological well-being and a direct correlation with many positive personal characteristics (purposefulness, persistence, selfefficacy, self-confidence, etc.). It has been found out that hardiness acts as an essential tool for successful functioning in society and acts as a kind of protective mechanism against the adverse effects of stress on mental and physical health and performance.

\section{Conclusions}

1. The theoretical basis of modern research of the scientific and professional community concerning the phenomenon of "hardiness" is formed by the works of famous American scientist S. Maddi, who defined this concept as the personality pattern of attitudes and strategies that helps people turn stressful circumstances from potential disasters into growth opportunities instead [26].

2. Hardiness is one of the most powerful resources that can help improve the physical and mental health of orphans and children left without parental care for successful adaptation in stressful situations and coping with difficult life situations. 
3. The results of the empirical part of the study have enabled us to distinguish the following features of hardiness in adolescent orphans of senior classes:

- the hardiness of adolescent orphans is one of the significant factors of the readiness of adolescent orphans for independent life and post-boarding socialization, while it has been found out that about $70 \%$ of high school leavers have a low or below average level of readiness for post-boarding socialization;

- the test results let us single out two groups of adolescents and determine the specific features of the psychological portrait characteristic of representatives of each group: group 1 ( 21 people $-32 \%$ of the sample) includes adolescents with an average and above average level of readiness for post-boarding socialization and group 2 (43 people $-68 \%$ of the sample) includes adolescents with a level of readiness below average and low.

- Most of the adolescent orphans and children left without parental care who live an orphanage have a level of readiness below average or low. At the same time, we have found out in the course of the study that the initial social skills are generally formed in this group of adolescents: they can enter into a conversation with other people, but have difficulty maintaining a conversation, expressing themselves in it, broadcasting information to another person and conveying their opinion to the interlocutor. The adolescents experience obvious difficulties, up to complete inability, in making decisions and planning upcoming actions and productively resolving a conflict situation, they are incapable of negotiating and defending their interests.

The adolescents are not psychologically ready to independently resolve issues related to their future social development, and are in a situation of uncertainty in their life choices. External circumstances are recognized by them as the main source of what is happening to a person. Self-contained reasons are either denied by them or, which is quite common, are repressed into the subconscious.

Summing up, we emphasize that, in our opinion, the low indicators of hardiness as well as of some specific subscales (involvement, control, risk taking) should be corrected by creating a set of measures (training programs, educational mentoring programs, etc.) to increase the general level of adolescent orphans' hardiness as well as its components for more favourable development and personal empowerment.

\section{References}

1. E.N. Osin, E.I. Rasskazova, Vestnik MGU. Series 14: Psychology 2, 147-165 (2013).

2. C.R. Rogers, R.F. Dymond, IL: University of Chicago Press, Chicago (1954).

3. M.I. Rozhkov, Educational Process: Study of Effectiveness. Moscow, 64-66 (2000).

4. O.V. Trishina, Methods of Psychological and Pedagogical Testing in Post-boarding Support of Graduates of Public Education Institutions. URL: https://urok.1 sept.ru/articles/648445

5. M. Rokeach, Value Survey (Sunnyvale, Calif., HalgrenTests, 1967).

6. S.S. Bubnova, Methodology for Testing Personal Value Orientations (Moscow, 1995).

7. S.R. Maddi, Springer briefs in psychology, New York-London, 88 (2013). DOI: 10.1007/978-94-007-5222-1_6

8. S.C. Kobasa, Journal of Personality and Social Psychology 37 (1), 1-11, (1979).

9. S.R. Maddi, Consulting Psychology Journal 54, 175-185 (2002). DOI: 10.1037/10614087.54.3.173

10. P.T. Bartone, Military Psychology 18, 131-148 (2006). 
11. P.T. Bartone, S.W. Hystad, J. Eid, and J.I. Brevik, Resilience Factors for Alcohol Abuse, Military Medicine 177, 517-524 (2012). DOI: 10.7205/MILMED-D-11-00200

12. D.E. Clarke, Social Behavior and Personality 23 (3), 285-286 (1995). DOI: 10.2224/sbp.1995.23.3.285

13. P.T. Bartone, D.R. Kelly, M.D. Matthews, International Journal of Selection and Assessment 21 (2), 200-210 (2013).

14. C.M. Kowalski, J.A. Schermer, Hardiness, Psychological Reports 122 (6), 2096-2118 (2019).

15. S.R. Maddi, M.D. Matthews, D.R. Kelly, [et al.], Military Psychology, 29 (5), 355-358 (2017). DOI: $10.1037 / \mathrm{mil} 0000145$

16. S.R. Maddi, L.M. Erwin, C.L. Carmody, B.J. Villarreal, M. White, K.K. Gundersen, The Journal of Positive Psychology 8 (2), 128-134 (2013). DOI: 10.1080/17439760.2012.758306

17. A.G. Aleksandrov, P.I. Lukyanenok, Scientific Review. Medical Sciences 6, 5-14 (2016).

18. C.D. Ryff, C.L. Keyes, Journal of Personality and Social Psychology 69 (4), 19-27 (1995). DOI: $10.1037 / / 0022-3514.69 .4 .719$

19. N. Bradburn, The Structure of Psychological Well-Being (Chicago, Aldine Pub. Co., 1969).

20. E. Diener, Journal of Happiness Studies 7, 397-404 (2006). DOI: 10.1007/s10902-0069000-y

21. Y. Kochetova, O. Ragulina, Collection of abstracts of the participants of the fifth allRussian Scientific-Practical Conference on Developmental Psychology, Moscow (2015).

22. T.V. Kornilova, Vestnik of Kostroma State University 26 (4), 223-229 (2020). DOI: 10.34216/2073-1426-2020-26-4-223-229

23. E.A. Bayer, Ph.D. Dis. Moscow (2013).

24. D.Sh. Dzhalilov, Young Scientist 50 (288), 450-455 (2019).

25. T.N. Yusupova, Personal Hardiness as a Reserve of Psychological Safety and Sociopsychological Adaptation of Orphans. Applied Psychology, Safety of the Interaction Environment: Materials of the II Regional Scientific-practical Conference for Practicing Psychologists, Young Scientists and Students. Yekaterinburg, 87-91 (2008).

26. S.R. Maddi, R.H. Harvey, D.M. Khoshaba, M. Fazel, and N. Resurreccion, Hardiness Training Facilitates Performance in College, Journal of Positive Psychology 4, 566577, (2009). DOI: 10.1080/17439760903157133 